\title{
Epigenetic silencing of miR-181b contributes to tumorigenicity in colorectal cancer by targeting RASSF1A
}

\author{
LUN-DE ZHAO $^{1}$, WEI-WEI ZHENG ${ }^{2}$, GAO-XIANG WANG ${ }^{1}$, XIAO-CHUN KANG ${ }^{3}$, \\ LEI QIN ${ }^{4}$, JUAN-JUAN JI ${ }^{4}$ and SHA HAO ${ }^{5}$ \\ Departments of ${ }^{1}$ Emergency, ${ }^{2}$ General Surgery, ${ }^{3}$ Oncology, ${ }^{4}$ Gastroenterology, The First Affiliated Hospital of \\ Xinxiang Medical University, Xinxiang, Henan 453100; ${ }^{5}$ Department of Medical Oncology, \\ Jingmen Traditional Chinese Medicine Hospital, Jingmen, Hubei 448000, P.R. China
}

Received October 30, 2015; Accepted January 20, 2016

DOI: $10.3892 /$ ijo.2016.3414

\begin{abstract}
Aberrant microRNA expression is common in colorectal cancer and DNA methylation is believed to be responsible for this alteration. In this study, we performed evaluation in vivo and in vitro to determine the role of miR-181b as a potential diagnostic and prognostic biomarker in colorectal cancer. Ninty-seven pairs of colorectal cancer tissues and adjacent normal tissues were collected. The expression level and methylation status of miR-181b was determined in tissue samples and multiple colorectal cancer cell lines. RASSF1A, a predicted target gene of miR-181b, was investigated in vitro. Further mechanistic explorations were conducted. It was found that miR-181b expression was frequently downregulated in cancer samples. This lower expression level resulted from higher hypermethylation in cancer tissue and was closely related to TNM stage. Following artificial synthesis of miR$181 \mathrm{~b}$ stimulation, colorectal cancer cell proliferation was greatly inhibited in CRC cells while apoptosis percentage markedly increased. miR-181b achieved the tumor suppressive effects via direct targeting of the RASSF1A gene. This study indicated the clinical significance of miR-181b and the influence of miR-181b promoter region in epigenetic silencing of tumorigenicity in colorectal cancer, and implied the possible usage of miR-181b as a diagnostic and prognostic biomarker in colorectal cancer.
\end{abstract}

\section{Introduction}

Colorectal cancer (CRC) has one of the highest prevalence rates of solid tumor world-wide and thus represents a significant financial burden for society $(1,2)$. It is a practical issue to identify effective diagnostic and prognostic biomarkers. The more we understand about the innate biological mechanism of

Correspondence to: Dr Sha Hao, Department of Medical Oncology, Jingmen Traditional Chinese Medicine Hospital, 5 Xiangshan 3rd Road, Jingmen, Hubei 448000, P.R. China

E-mail: doctor_hao@yeah.net

Key words: colorectal cancer, microRNA, methylation, RASSF1A, apoptosis
CRC, the better the optimal clinical outcome will be to benefit patients and reduce the burden of this disease.

In the past, research and clinical practice paid most attention to protein coding gene alteration and subsequently effect in CRC initiation and progression $(3,4)$. Nowadays, a class of small (18-24 nucleotide) non-coding RNAs, microRNAs (miRNAs), are focussed on considering their role in regulating the transcription of multiple target mRNAs (5). A decade ago, it was found in chronic leukemia studies that more and more miRNA molecules were confirmed to be involved in the occurrence and development of a variety of cancers including CRC (6-8). A previous study explored a panel of altered miRNAs in CRC and reported differential expression levels in patient samples (9). Both elevated miRNAs and decreased miRNAs were found from multiple study resources. Thus indicating the role of miRNAs in CRC progression (10-12).

Extensive research is being conducted in order to clarify the direct target of a specific miRNA, evaluating the feasibility of a specific miRNA as diagnostic and prognostic biomarker and regulation of the process. miR-181b was recognized as one of the most important miRNAs that regulate tumor initiation and progression $(13,14)$. A recently released case-control study reported downregulation of miR-181b in $30 \mathrm{CRC}$ tissue samples compared to paired control. In contrast, earlier study reported high expressed miR-181b in CRC samples $(15,16)$. This controversial result indicates that more research should be conducted to explore the role of miR-181b in CRC as well as the involved mechanisms.

A relatively large study group was recruited in the present study to further determine the expression of miR-181b in CRC tissues and paired normal tissues, and to evaluate the association between the miR-181b expression level and the clinicopathological factors. Epigenetic status of miR-181b was also investigated. In vitro functional study, including target genes identification, cell proliferation and invasion and metastasis ability, was also conducted in multiple colorectal cancer cell lines.

\section{Patients and methods}

Patients and tissue samples. Ethics Committee from the First Affiliated Hospital of Xinxiang Medical University 
approved the ethical requirements for this study. All the patients consented to the procedures of the molecular analysis. Moreover, tissues samples and adjacent normal tissues from 97 CRC patients, who underwent curative surgery without the use of chemotherapy in the First Affiliated Hospital of Xinxiang Medical University from July 2010 to August 2014, were analyzed and compared. The American Joint Committee on Cancer TNM system was used in order to determine the tumor burden. The CRC patient group consisted of 32 females and 65 males with a mean age of $61.34 \pm 11.27$ years. All tissue samples were frozen in liquid nitrogen at $-80^{\circ} \mathrm{C}$.

Cell lines and 5-aza-CdR treatment. Four commonly used colorectal cancer cell lines HCT-29, HCT116, SW1116, SW480 and the normal colon cell line CCD-18co were obtained from the Chinese Academy of Sciences (Beijing, China) and supplemented with RPMI-1640 containing 10\% fetal bovine serum (FBS) (both from Gibco, Grand Island, NY, USA) in 5\% $\mathrm{CO}_{2}$ incubator until 70\% confluence. 5-Aza-CdRr (Sigma-Aldrich, St. Louis, MO, USA) diluted with DMSO was administered to the cultured media at concentrations of $5 \mu \mathrm{mol} / 1$, whereas, the control group comprising of untreated plates were only incubated with equal amounts of DMSO similarly to the cultured media. After 3 days of treatment, the cells were collected for further analysis.

Cell proliferation and colony formation. To evaluate cell viability, $1 \times 10^{4}$ cells from mock control and transfected groups were seeded in the 96-well plates for $48 \mathrm{~h}$. The plates were added with $100 \mu \mathrm{l}$ MTT (Sigma-Aldrich) for each well and incubated for $4 \mathrm{~h}$. Surviving cells developed purple formazan crystals and were air dried at room temperature for $30 \mathrm{~min}$. The cell viability was quantified at the absorbance value A490 using iMark Microplate absorbance reader (Bio-Rad, Hercules, CA, USA).

Colony formation assay was performed in transfected and mock control groups. Cells $\left(1 \times 10^{3}\right)$ were seeded in a 6 -well plate in each well, and incubated for $72 \mathrm{~h}$ at $37^{\circ} \mathrm{C}$. The colonies were then fixed with $20 \%$ methanol for $10 \mathrm{~min}$ at room temperature following $0.1 \%$ crystal violet (Sigma-Aldrich) staining. The number of colonies for each group was counted.

DNA methylation analysis. DNA was bisulfite modified using the commercial DNA methylation kit (Invitrogen, Carlsbad, CA, China). PCR primers were designed using MethPrimer software miR-181b primer, forward, 5'-TAAGCGATAGAA GGTAGTG-3' and reverse, 5'-CAAACTACCTTATTATAA TTATAACA-3'.

The PCR cycle conditions were as follow: initial denaturation at $94^{\circ} \mathrm{C}$ for $7 \mathrm{~min}, 45$ cycles at $94^{\circ} \mathrm{C}$ for $30 \mathrm{sec}, 52^{\circ} \mathrm{C}$ for $30 \mathrm{sec}$, and $72^{\circ} \mathrm{C}$ for $30 \mathrm{sec}$.

A total of $6 \mu 1$ amplified PCR was used for electrophoresis in a $2 \%$ gel. To increase the efficacy of this procedure, MSPs were analytically validated using DNA methylated with $\mathrm{CpG}$ Methylase (M.SssI) (New England Biolabs, Hitchin, Herts, UK) from placental tissue as positive control, and normal human lymphocyte DNA as unmethylated control.

Apoptosis analysis. Cell apoptosis analysis was performed by flow cytometry with commercial Annexin V-FITC apoptosis detection kit I (BD Pharmingen, San Diego, CA, USA). The nuclear apoptosis was evaluated by Hoechst 33342 (Qiagen, Hilden, Germany) staining according to the instructions of the supplier. The morphology was detected and recorded by a fluorescent microscope (Nikon 3200; Nikon, Tokyo, Japan) at excitation of $350 \mathrm{~nm}$ and absorbance at $460 \mathrm{~nm}$.

Exogenous miRNA transfection. Cells were seeded into cell culture plates at density of $1 \times 10^{6}$ and harvested following $48 \mathrm{~h}$ incubation when cells reached $70 \%$ confluence. Exogenous miRNA-181b (GenePharma, Shanghai, China) was transfected in to cells by using Lipofectamine 2000 (Invitrogen) at final concentration of $50 \mathrm{nM}$ according to the manufacturer's protocol. Mock control was also set up with same procedure, and quantitative PCR (qPCR) was performed $48 \mathrm{~h}$ posttransfection.

RNA interference. For siRNA, the following sequences were used: 5'-GACCUCUGUGGCGACUUCA-3', 5'-GGUUUUG GAUCUUGAAUGU-3' and 5'-GGAUAUCCUUAUCAGA GCU-3'. All oligonucleotides (Thermo Fisher Scientific, Waltham, MA, USA) were delivered into HeLa cells and were harvested $48 \mathrm{~h}$ after transfection. Knockdown efficiency was validated with RT-PCR.

Luciferase report system identifies miR-181b target gene. Transfection of wild and mutated miR-181b binding sequences (Sangon, Shanghai, China) in the 3'UTR of RASSF1A were carried out in SW480 cells with pMIR-Report Luciferase plasmid (Life Technologies, Carlsbad, CA, USA) at final concentration of $500 \mathrm{ng}$ for $24 \mathrm{~h}$ incubation, and $50 \mathrm{nM} \mathrm{miR}$ $181 \mathrm{~b}$ or miR-control vector were next transfected into cells for further $24 \mathrm{~h}$ incubation. Comparison of luciferase activity from different groups was then conducted.

Real-time qPCR. TRIzol (Invitrogen) was used to extract total cellular RNA from the CRC tissue samples and cell pellets as per instructions of the manufacturer. UV spectrophotometer was used to detect the purity and concentration of total RNA, which was diluted with water treated pyrocarbonate (DEPC). Then, liquid nitrogen was used to freeze and store the total RNA at $-80^{\circ} \mathrm{C}$. M-MLV Rtase cDNA Synthesis kit (Invitrogen) was used to synthesize complementary DNA (cDNA) stands with RNA as a template. In order to evaluate transcript expression, gene-specific primers were used in a $20 \mu 1$ reaction which contained $2 \mu \mathrm{l}$ of template cDNA, $10 \mu \mathrm{l}$ of 2X SYBR-Green Master Mix, $1 \mu \mathrm{l}$ of $10 \mu \mathrm{mol} / 1$ primers, $2 \mu 1$ of $\mathrm{ddH}_{2} \mathrm{O}$ and $4 \mu \mathrm{l}$ of $25 \mathrm{mmol} / \mathrm{M} \mathrm{Mg}^{2+}$. Then the solution was administered to a ABI Prism 7500HT sequence detection system (Applied Biosystems, Foster City, CA, USA) for the following sequence of cycles: $3 \mathrm{~min}$ at $95^{\circ} \mathrm{C}$ which was immediately followed by 40 consecutive cycles at $95^{\circ} \mathrm{C}$ for $10 \mathrm{sec}$ and lastly $30 \mathrm{sec}$ at $60^{\circ} \mathrm{C}$. Moreover, comparative cycle threshold (CT) method was applied to calculate the level of transcripts by using RNU48 as an endogenous control. The final results were calculated by using $2^{-\Delta \Delta \mathrm{Ct}}$ method. The method involved estimating $\Delta \mathrm{Ct}$ for each sample by subtracting the $\mathrm{Ct}$ value of genes from the $\mathrm{Ct}$ value of RNU48, which served as a controlled variable. However, $\mathrm{Ct}$ values of triplicates having a standard deviation of $<0.20$ 
were acceptable. The product of MSP was kept at $4^{\circ} \mathrm{C}$, and analyzed by gel electrophoresis.

Western blot analysis. Manufacturer's instructions were followed throughout the procedures (Abcam, Cambridge, UK). Briefly, cells were centrifuged and lysed in solution. Proteins were loaded into the wells of the SDS-PAGE gel along with molecular weight markers. Afterwards, electro-transference of proteins on nitrocellulose membrane took place, which was immediately followed by blocking the membrane overnight at $4^{\circ} \mathrm{C}$ or for $1 \mathrm{~h}$ at room temperature using $5 \%$ blocking solution. Moreover, the membranes were subjected to overnight incubation (at $4^{\circ} \mathrm{C}$ ) with various primary antibodies alongside horseradish peroxidase-conjugated secondary antibodies for $1 \mathrm{~h}$ (at room temperature). Anti- $\beta$-actin antibodies were obtained from Santa Cruz Biotechnology, Inc. (Santa Cruz, CA, USA) while anti-RASSF1A antibodies were from Cell Signaling Technology, Inc. (Danver, MA, USA).

Statistical analysis. SPSS 13.0 (SPSS Inc., Chicago, IL, USA) was used for all data in statistical analysis. Numerical data were performed with mean \pm standard deviation (SD). Statistical analysis was performed using the Student's t-test. Category data are displayed with actual number and percentage. Depending on sample size, Chi-square test or Fisher's exact test were performed. Each experiment was carried out in triplets or repeated at least twice. P-value $<0.05$ was adopted as significant.

\section{Results}

Declined expression of miR-181b in CRC cell lines and tumor tissues. The expression of miR-181b was first detected in 97 pairs of CRC tissues and adjacent normal tissue samples. Compared to normal tissue samples, the tumor tissues exhibited lower levels of miR-181b in 65 out of 97 samples (Fig. 1A). Furthermore, four primary colorectal carcinoma cell lines (HCT-29, HCT116, SW480 and SWS116) were analyzed revealing the universal downregulation of miR-181b in the tested CRC cell lines (Fig. 1B). Because of the lowest expression level of miR-181b in SW480, it was selected for further functional study.

Association of reduced miR-181b expression and clinicopathological features in CRC. Based on relative expression levels in tumor and normal tissue (tumor/normal <0.05), patients were divided into lower expression and higher expression (Table I). Results revealed a tightly linked association between the expression of miR-181b and CRC clinical stage. The patients with downregulation of miR-181b expression were statistically associated with high differential grade $(\mathrm{P}=0.042)$ and advanced stage $(\mathrm{P}=0.028$, Fisher's exact test).

miR-181b is epigenetically silenced in colorectal cancer. Compared to adjacent non-tumor tissues, our MSP results indicated more frequent miR-181b epigenetic silencing in the 97 tumor tissues $(\mathrm{P}<0.05)$ (Fig. 2A). Receiver operating characteristics and the area under the curve (AUC) derived from receiver operating characteristics further confirmed higher methylation of miR-181b in CRC than that of the null hypothesis $(\mathrm{P}<0.05$; AUC $=0.72$; 95\% CI, 0.54-0.86) (Fig. 2B).
Table I. Association between miR-181b mRNA expression and methylation status and clinicopathological features in colorectal carcinomas.

\begin{tabular}{|c|c|c|c|c|c|c|}
\hline \multirow{2}{*}{$\begin{array}{l}\text { Clinical and } \\
\text { pathological } \\
\text { features }\end{array}$} & \multirow[b]{2}{*}{$\mathrm{N}$} & \multicolumn{4}{|c|}{ miR-181b } & \multirow[b]{2}{*}{ P-value } \\
\hline & & Low & $\%$ & Higher & $\%$ & \\
\hline All cases & 97 & 65 & 67.0 & 32 & 33.0 & \\
\hline Age (years) & & & & & & 0.24 \\
\hline$<50$ & 29 & 17 & 26.2 & 12 & 37.5 & \\
\hline$\geq 50$ & 68 & 48 & 73.8 & 20 & 62.5 & \\
\hline Gender & & & & & & 0.37 \\
\hline Female & 42 & 24 & 36.9 & 18 & 56.3 & \\
\hline Male & 55 & 41 & 63.1 & 14 & 43.7 & \\
\hline TNM stage & & & & & & 0.028 \\
\hline T1N0M0 & 33 & 17 & 26.2 & 16 & 50.0 & \\
\hline T2NOM0 & 38 & 26 & 40.0 & 12 & 37.5 & \\
\hline T3N0M0 & 26 & 22 & 33.8 & 4 & 12.5 & \\
\hline $\begin{array}{l}\text { Tumor } \\
\text { differentiation }\end{array}$ & & & & & & 0.042 \\
\hline Moderate & 60 & 49 & 75.4 & 11 & 34.4 & \\
\hline Well & 37 & 16 & 24.6 & 21 & 65.6 & \\
\hline Dukes' stage & & & & & & 0.037 \\
\hline A & 38 & 21 & 32.3 & 17 & 53.1 & \\
\hline B & 59 & 44 & 67.7 & 15 & 46.9 & \\
\hline $\operatorname{miR}-181 b$ & & & & & & $<0.01$ \\
\hline Unmethylation & 36 & 5 & 7.7 & 31 & 96.9 & \\
\hline Methylation & 61 & 60 & 92.3 & 1 & 3.1 & \\
\hline
\end{tabular}

The randomly selected representative results of MSP analysis in CRC tumor tissues and paired adjacent non-tumor tissues are presented in Fig. 2C. Furthermore, the universal methylated status in the four CRC cell lines was detected. Following treatment with $5 \mathrm{nmol} / \mathrm{ml} 5$-AZA, significant demethylation occurred in all cell lines (Fig. 2D).

miR-181b inhibits colorectal cancer cell proliferation. In the next cell functional study, miR-181b mimic was introduced into cells. Transfected efficiency evaluation with qRT-PCR revealed that miR-181b increased by $>4$-fold in miR-181b transfected SW480 cells (Fig. 3A). Furthermore, the MTT proliferation assay showed that cell growth rate was reduced in miR-181b mimic-transfected SW480 cells when compared with control cells (Fig. 3B). Colony formation assay provided visible evidence in which miR-181b mimic-transfected SW480 cells had less colony formation compared to the control parental cells (Fig. 3C).

miR-181b targets 3'UTR of the tumor suppressor RASSF1A. We searched miR-181b putative targets using online databases (TargetScan, microRNA.org and PicTar). To validate this interaction, we introduced a mutant 3'UTR fragment of RASSF1A in our experiment (Fig. 4A). Results showed that the relative luciferase activity of RASSF1A wild-type was significantly 

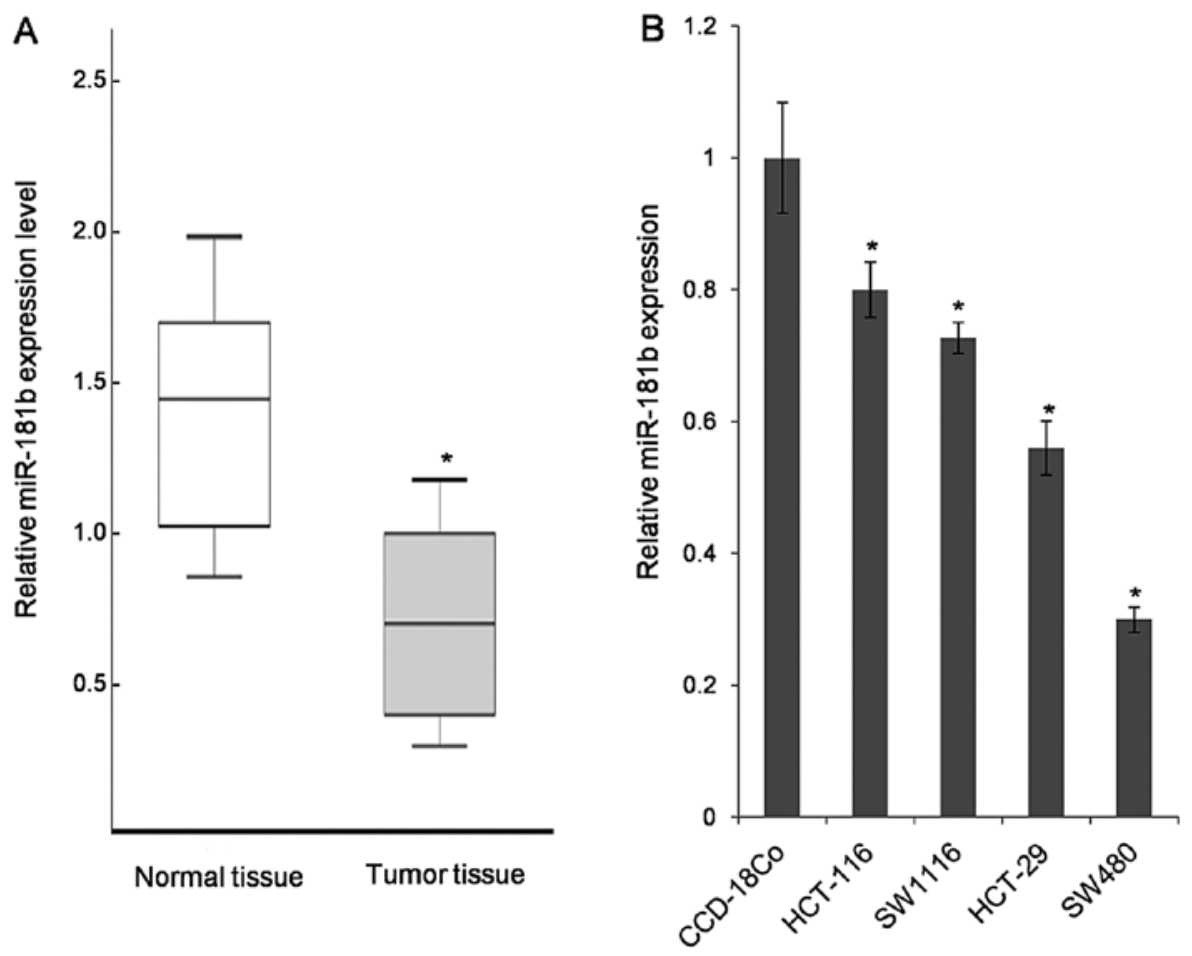

Figure 1. Determination of miR-181b expression in paired colorectal cancer tissue samples and CRC cell lines. (A) Significantly reduced expression of miR-181b was observed in 97 colorectal cancer tissues compared to corresponding non-tumor tissues. The data are presented in the box-plot ("P<0.05). (B) Relative expression of miR-181b was universally downregulated in all the tested colorectal cell lines HCT-116, HCT-29, SW1116 and SW480 compared to the immortalized normal colon epithelial cell line CCD-18Co ( $(\mathrm{P}<0.05)$.
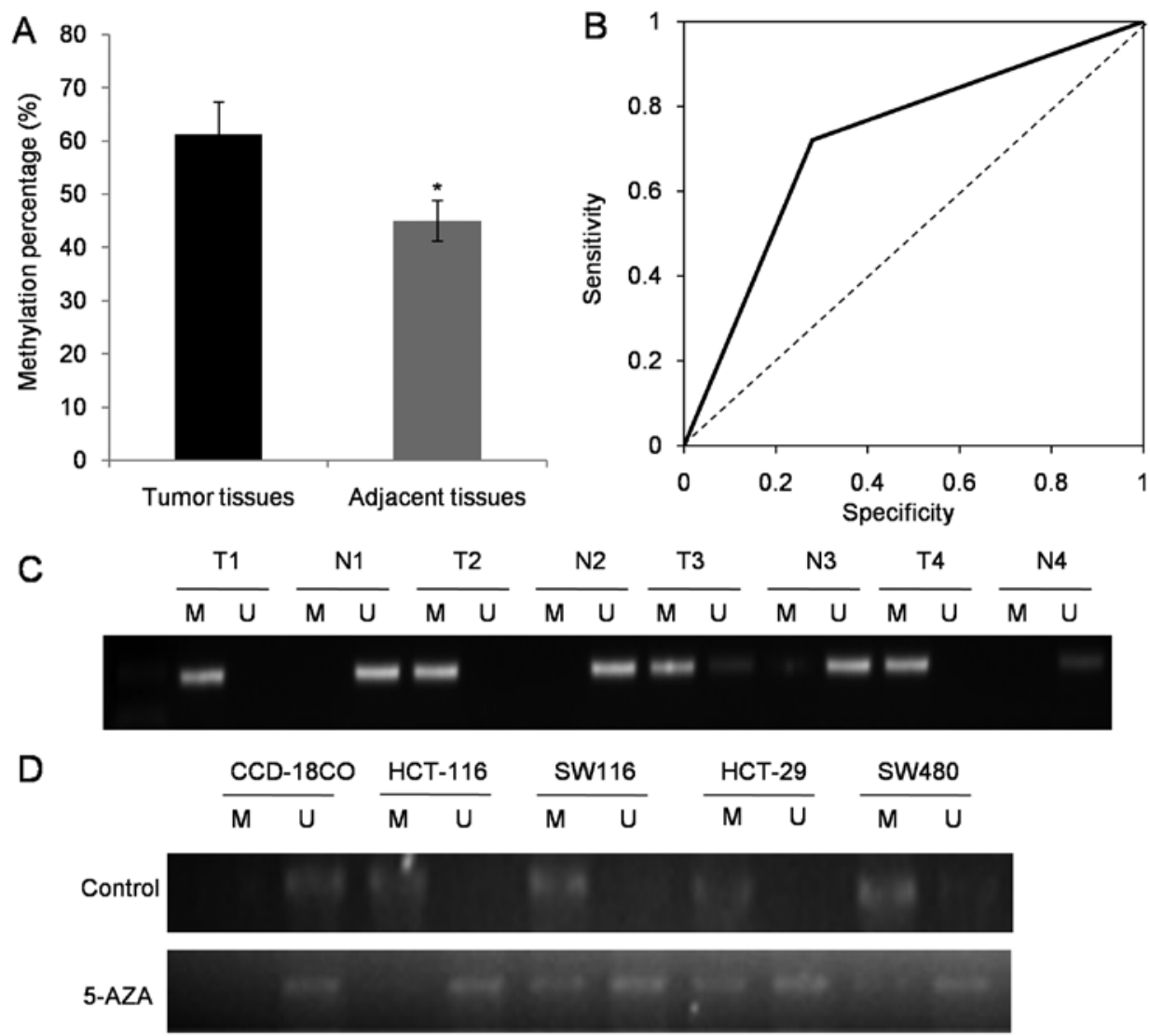

Figure 2. Methylation status of miR-181b CpG island in patient tissue and cell lines. (A) Methylation distribution of miR-181b CpG island in $97 \mathrm{CRC}$ tumor tissues and paired adjacent non-tumor tissues ("P<0.05). (B) The receiver operating characteristics curve (ROC) of methylation status of miR-181b. (C) PCR bands represent the results of MSP analysis of miR-181b in colorectal cancer tissues. T, tumor tissue; N, normal tissues. Four paired samples were randomly selected. (D) MSP analysis for miR-181b methylation in CRC cell lines pre- and post-5 nmol/ml demethylation agent 5-Aza. M, methylation; U, unmethylation. 

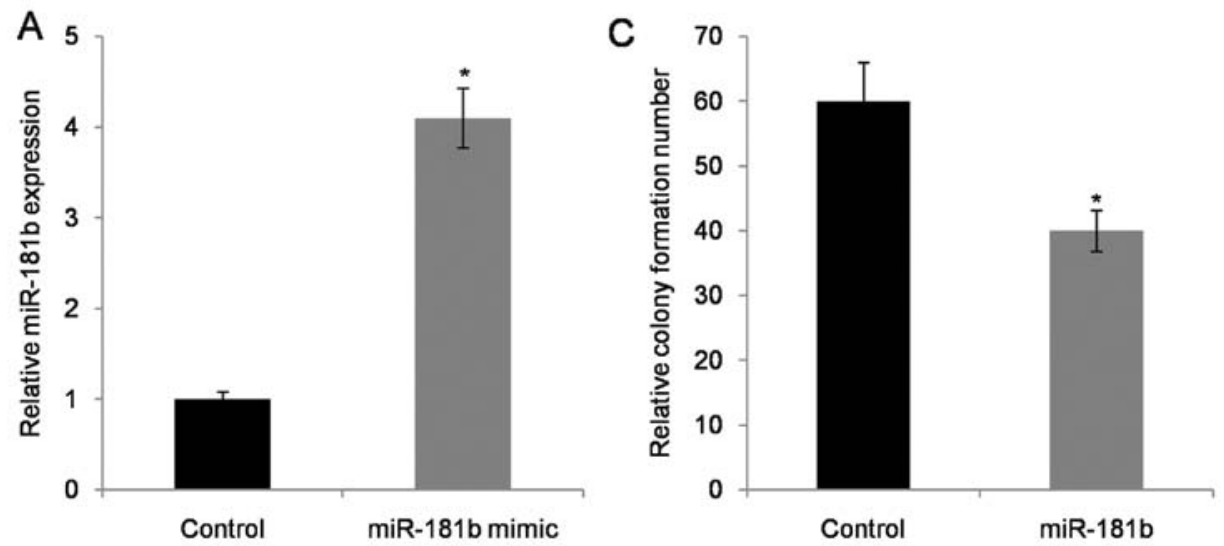

B

D

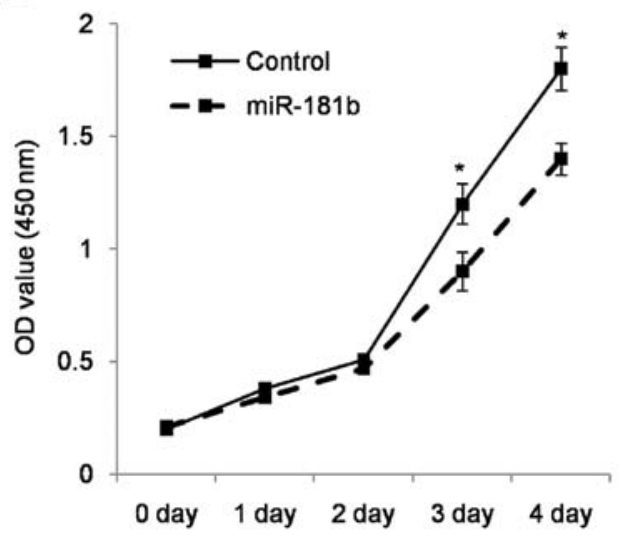

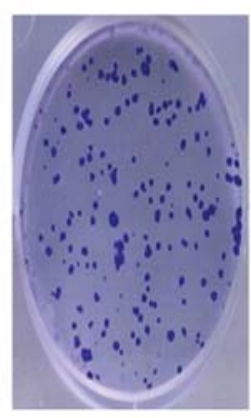

Control

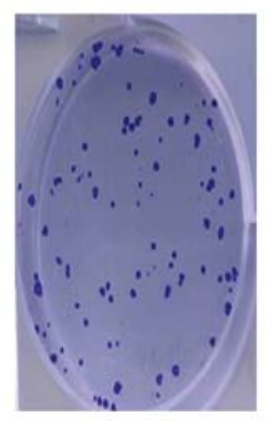

miR-181b

Figure 3. Ectopic enhanced expression of miR-181b inhibits cell proliferation. (A) The miR-181b mimic transfection efficiency was evaluated with qRT-PCR in SW480 cells. (B) SW480 cells were respectively transfected with miR-181b mimics or mock control at a final concentration of 50 nM and continually incubated for 4 days. Cell proliferation of miR-181b transfected cells exhibited a significant decrease after 3-day incubation compared to mock control cells. (C) Colony formation assay further confirmed that SW480 cells transfected with $50 \mathrm{nM}$ of miR-181b mimics has less colonies compared to the mock control cells. (D) Representative images of colony formation in miR-181b or mock control cells. All experiments was performed in at least triplicate and presented as means \pm SD. ${ }^{*} \mathrm{P}<0.05$ vs. mock control cells.

elevated by miR-181b compared to RASSF1A mutation type and control mimics (Fig. 4B). The mRNA expression and protein levels of RASSF1A, after transfecting SW480 cells with miR-181b, significantly increased compared with control transfection (Fig. 4C and D). miR-181b and RASSF1A were positively expressed in CRC cell lines and specimens. Fifty patients were randomly chosen to evaluate the clinical relevance of the expression of miR-181b and RASSF1A. We found that the downregulated miR-181b was statistically correlated with decreased expression of RASSF1A in the CRC tissues (Fig. 4E).

RASSF1A mediated miR-181b-induced colorectal cancer cell apoptosis. To elucidate RASSF1A-mediated effects of miR-181b on CRC cell apoptosis, RASSF1A knockdown cells were used (Fig. 5A). Flow cytometry was utilized to examine the percentage of cell apoptosis in SW480 cells. As expected, apoptotic percentage increased in cells with miR-181b mimic treatment, which was evaluated by Annexin V staining, and no significant apoptosis was observed in RASSF1A knockdown cells (Fig. 5B and C). Morphology of the Hoechst 33342 stained cells further confirmed the enhanced apoptotic rate in miR-181b mimic-transfected cells (Fig. 5C).

\section{Discussion}

The present study found that downregulated miR-181b was a frequent event in 97 human CRC samples. The statistical association between lower expression of miR-181b and tumor stage was further observed. Together, it suggested miR-181b may be involved in colorectal cancer carcinogenesis and progression. Our results found the methylation status of $\mathrm{miR}-181 \mathrm{~b} \mathrm{CpG}$ island to be universal in colorectal cell lines and it is also responsible for tightly regulating the miR-181b expression in tissues and cells. This suggested that evaluation of methylation status in miR-181b is a potential diagnostic marker for CRC. Furthermore, overexpression of miR-181b induced apoptosis in CRC cells and cell growth inhibition was observed. miR-181b achieved this regulation function through direct targeting of the RASSF1A gene. The positive correlation between miR181b and RASSF1A in CRC tissue samples further validates this observation. Also, our results revealed the significantly positive correlation between $\mathrm{miR}-181 \mathrm{~b}$ in tissue and circulating miR-181b (Fig. 6), which suggested the potential biomarker role of miR-181b in clinic.

Aberrant transcription of microRNAs in CRC is diverse due to the complex regulation of miRNAs. Previous studies reported 

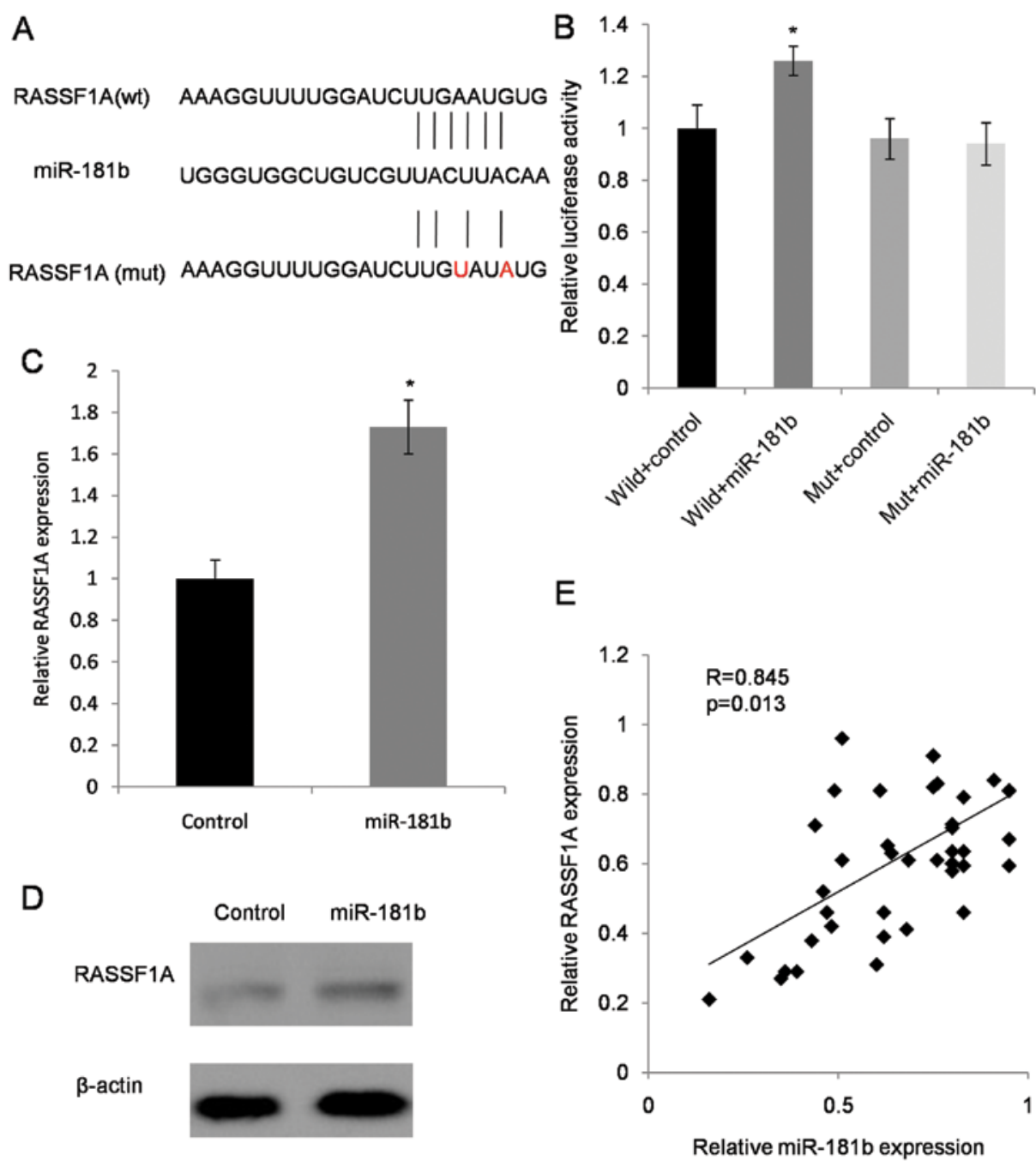

Figure 4. miR-181b targets 3'UTR of RASSF1A and induces RASSF1A expression. (A) Putative binding sites of miR-181b targeted the 3'UTR of RASSF1A. Two bases were mutated in RASSF1A binding sequence (Red). (B) Relative luciferase activity of miR-181b mimics upregulated by miR-181b in wild-type 3'UTR of RASSF1A, but no influence in mutant 3'UTR of RASSF1A. (C) Upregulation of RASSF1A mRNA in SW480 cells was reported by qPCR analysis after post-transfection with miR-181b for $48 \mathrm{~h}$. (D) Enhanced RASSF1A protein level was observed in miR-181b stimulated cells by western blot analysis (E) A statistically significant positive correlation between miR-181b and RASSF1A expression in CRC specimens is presented analyzed with Pearson's correlation analysis. " $\mathrm{P}<0.05$ vs. control. All experiments were performed at least in triplicate and are presented as the means \pm SD.

overexpression of miRNAs such as miR-21, and let-7g in CRC (9), while other studies provided evidence for lower expression of miRNAs including miR-31 and miR-92a (14). As for miR-181b, both upregulation and downregulation was reported in CRC studies $(9,15,17)$. The expression level of miR-181b was reported to correlate with chemo-response in colorectal cancer and with poor survival in stage III colorectal cancers (18-20). While another miRNA study containing 113 CRC cases and 89 controls, declared that the lower expression of miR-181b can be used as a noninvasive biomarker for the diagnosis of CRC with relatively high sensitivity and specificity (9). The present study found downregulated miR-181b in 97 human CRC samples. The different results may be explained by the diversity in the characteristics of various types of cancers, polymorphism in miRNA coding region or binding sites.

Epigenetic mechanisms are considered to be responsible for aberrant microRNA expression levels (21). Multiple studies have reported the frequency of hypermethylation of miRNAs in colon tumors and cell lines such as let-7, miR-34, miR-342, miR-345, miR-9, miR-129 and miR-137 (22).
However, no study reported methylation of miR-181b in colorectal cancer. Our results indicate that the methylation status of miR-181b was universal in colorectal cell lines and this methylation is thought to lead to reduced expression in tissues and cells.

It is commonly accepted that microRNAs can contribute to global epigenetic regulation in CRC (23-25). For example, miR-143 is found to be a tumor suppressor which directly targets DNA methyltransferase 3A (DNMT3A) and leads to decreased DNMT3A in CRC tissues (26). This study chose RASSF1A as a target candidate according to the widely used miRNA target predication databases $(27,28)$. The binding effect between RASSF1A and miR-181b was confirmed by the luciferase reporter. Further knockdown experiment revealed that RASSF1A mediated miR-181b induced apoptosis in CRC cell lines. Their positive correlation was also validated in tissue samples. RASSF1A is a well-known tumor suppressor and downregulated expression of RASSF1A has been reported in CRC (29-31). The association outcomes observed between miR-181b and RASSF1A mRNA expression indicated that exog- 

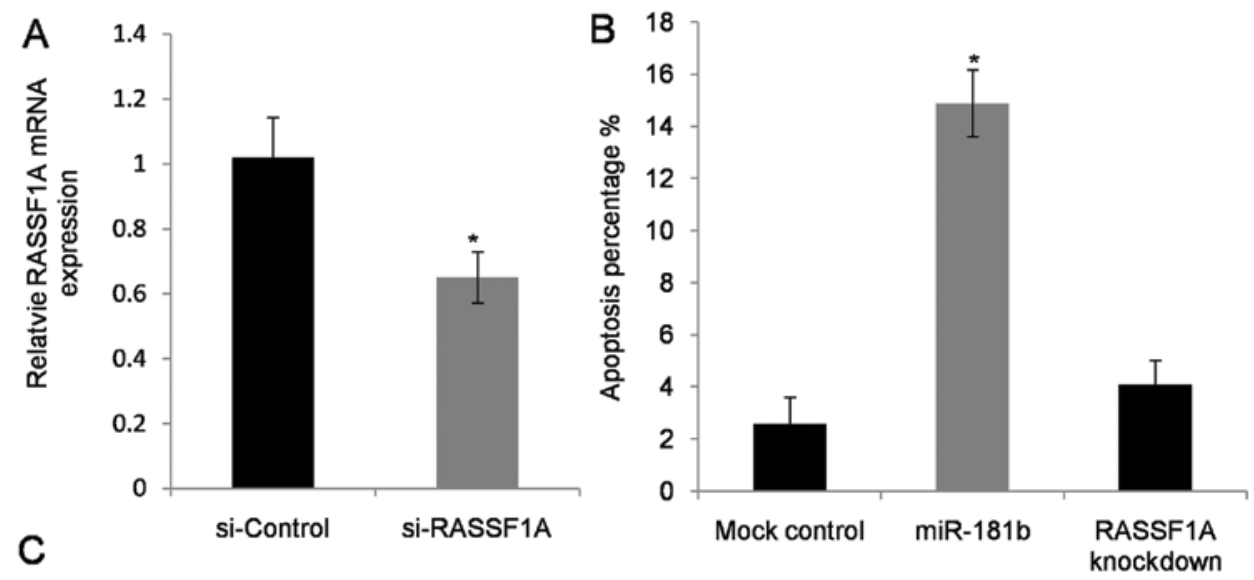

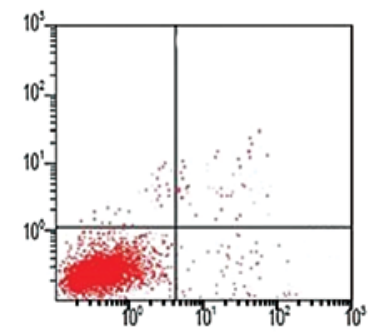

Mock control

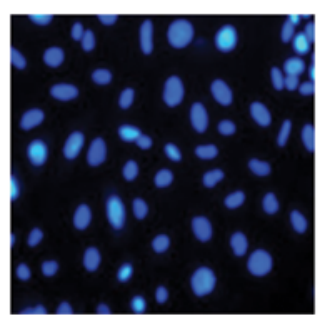

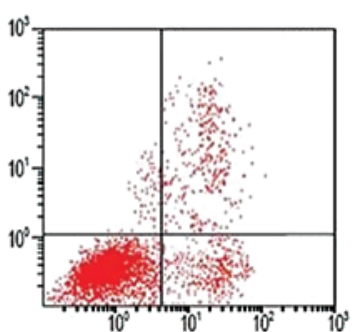

miR-181b

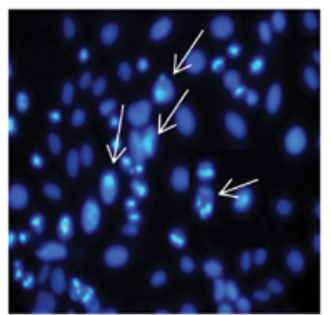

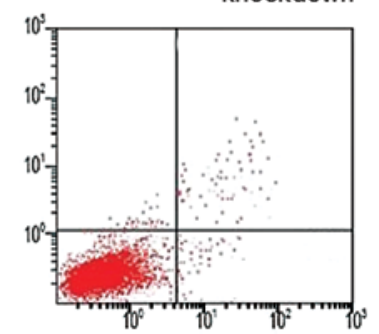

RASSF1A knockdown

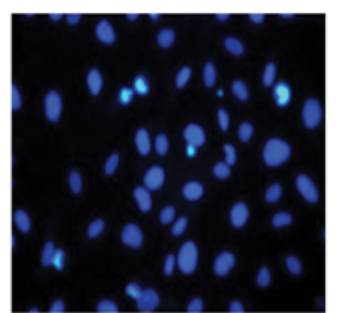

Figure 5. The effect of miR-181b on apoptosis of SW480 cells. (A) RASSF1A knockdown efficiency was validated by qRT-PCR. (B) Overexpression of miR-181b promoted apoptotic process in CRC cells. (C) Representative flow cytometry results of apoptotic cell distribution stained with PI and Annexin V-FITC at $48 \mathrm{~h}$ post-transfection. Hoechst 33342 stained transfected cells demonstrated apoptotic morphology with condensation of the nuclear material and formation of apoptotic bodies (arrow) in SW480 cells (magnification, x200). All experiments was performed at least in triplicate and are presented as the means \pm SD. ${ }^{*} \mathrm{P}<0.05$ vs. mock control cells.

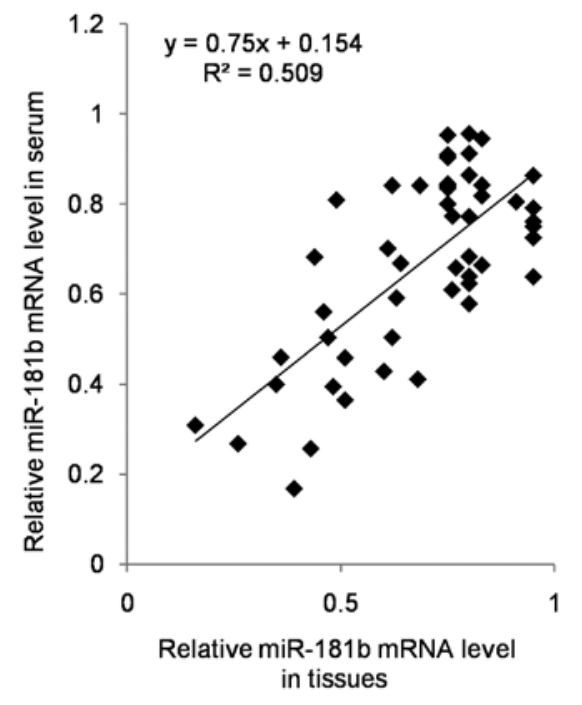

Figure 6. Relationship between circulating and tissue miR-181b expression. A statistically significant positive correlation between miR-181b expression in CRC specimens and plasma was expressed with Pearson's correlation analysis. $\mathrm{R}=0.713$ and $\mathrm{P}<0.05$. All experiments were performed at least in triplicate and are presented as the means \pm SD. enous miR-181b successfully stimulated RASS1A transcription level and subsequently contributed to tumor suppression. Our result therefore obtained a detailed explanation with regards to elevated cell apoptosis following miR-181b mimic stimulation and further provide evidence that miRNA-target interactions primarily influenced the target mRNA translation efficiency.

In general, frequent hypermethylation at the promoter region of miR-181b mainly contributes to the lower expression of miR-181b and advanced clinical stage in colorectal cancer tissues. Functionally, overexpression of miR-181b influences tumorigenicity of CRC cells in multiple levels by directly binding to tumor suppressor RASSF1A and stimulating its expression. This study provides evidence for the clinical significance of miR-181b methylation status as diagnostic biomarker and potential target in colorectal cancer treatment.

\section{Acknowledgements}

We wish to acknowledge the evaluators, research assistants, and particularly the patients and families who participated in this study. 


\section{References}

1. Siegel R, Desantis C and Jemal A: Colorectal cancer statistics, 2014. CA Cancer J Clin 64: 104-117, 2014.

2. Siegel R, Ma J, Zou Z and Jemal A: Cancer statistics, 2014. CA Cancer J Clin 64: 9-29, 2014

3. Shah R, Jones E, Vidart V, Kuppen PJ, Conti JA and Francis NK: Biomarkers for early detection of colorectal cancer and polyps: Systematic review. Cancer Epidemiol Biomarkers Prev 23: $1712-1728,2014$

4. Jimenez CR, Knol JC, Meijer GA and Fijneman RJ: Proteomics of colorectal cancer: Overview of discovery studies and identification of commonly identified cancer-associated proteins and candidate CRC serum markers. J Proteomics 73: 1873-1895, 2010.

5. Xuan Y, Yang H, Zhao L, Lau WB, Lau B, Ren N, Hu Y, Yi T, Zhao X, Zhou S, et al: MicroRNAs in colorectal cancer: Smal molecules with big functions. Cancer Lett 360: 89-105, 2015.

6. Yang X, Zhong J, Ji Y, Li J, Jian Y, Zhang J and Yang W: The expression and clinical significance of microRNAs in colorectal cancer detecting. Tumour Biol 36: 2675-2684, 2015.

7. Amankwatia EB, Chakravarty P, Carey FA, Weidlich S, Steele RJ, Munro AJ, Wolf CR and Smith G: MicroRNA-224 is associated with colorectal cancer progression and response to 5 -fluorouracil-based chemotherapy by KRAS-dependent and -independent mechanisms. Br J Cancer 112: 1480-1490, 2015.

8. Taniguchi K, Sugito N, Kumazaki M, Shinohara $H$, Yamada N, Nakagawa Y, Ito Y, Otsuki Y, Uno B, Uchiyama K, et al: MicroRNA-124 inhibits cancer cell growth through PTB1/PKM1/PKM2 feedback cascade in colorectal cancer. Cancer Lett 363: 17-27, 2015.

9. Wang J, Huang SK, Zhao M, Yang M, Zhong JL, Gu YY, Peng H, Che YQ and Huang CZ: Identification of a circulating microRNA signature for colorectal cancer detection. PLoS One 9: e87451, 2014.

10. Zeng W, Tu Y, Zhu Y, Wang Z, Li C, Lao L and Wu G: Predictive power of circulating miRNAs in detecting colorectal cancer. Tumour Biol 36: 2559-2567, 2015.

11. Vaish V, Khare T, Verma M and Khare S: Epigenetic therapy for colorectal cancer. Methods Mol Biol 1238: 771-782, 2015.

12. Dassow $\mathrm{H}$ and Aigner A: MicroRNAs (miRNAs) in colorectal cancer: From aberrant expression towards therapy. Curr Pharm Des 19: 1242-1252, 2013.

13. Ma X, Becker Buscaglia LE, Barker JR and Li Y: MicroRNAs in NF-kappaB signaling. J Mol Cell Biol 3: 159-166, 2011.

14. Sun YC, Wang J, Guo CC, Sai K, Wang J, Chen FR, Yang QY, Chen YS, Wang J, To TS, et al: MiR-181b sensitizes glioma cells to teniposide by targeting MDM2. BMC Cancer 14: 611, 2014.

15. Bovell LC, Shanmugam C, Putcha BD, Katkoori VR, Zhang B Bae S, Singh KP, Grizzle WE and Manne U: The prognostic value of microRNAs varies with patient race/ethnicity and stage of colorectal cancer. Clin Cancer Res 19: 3955-3965, 2013.

16. Iliopoulos D, Jaeger SA, Hirsch HA, Bulyk ML and Struhl K: STAT3 activation of miR-21 and miR-181b-1 via PTEN and CYLD are part of the epigenetic switch linking inflammation to cancer. Mol Cell 39: 493-506, 2010.
17. Nakajima G, Hayashi K, Xi Y, Kudo K, Uchida K, Takasaki K, Yamamoto $\mathrm{M}$ and Ju J: Non-coding MicroRNAs hsa-let-7g and hsa-miR-181b are Associated with Chemoresponse to S-1 in Colon Cancer. Cancer Genomics Proteomics 3: 317-324, 2006.

18. Xi Y, Formentini A, Chien M, Weir DB, Russo JJ, Ju J, Kornmann $\mathrm{M}$ and Ju J: Prognostic values of microRNAs in colorectal cancer. Biomark Insights 2: 113-121, 2006.

19. Xu R, Ma N, Wang F, Ma L, Chen R, Chen R, Kebinu M, Ma L Han Z, Ayixiamu, et al: Results of a randomized and controlled clinical trial evaluating the efficacy and safety of combination therapy with Endostar and S-1 combined with oxaliplatin in advanced gastric cancer. Onco Targets Ther 6: 925-929, 2013.

20. Watanabe K, Kawahara H, Enomoto H, Toyama Y, Akiba T and Yanaga K: Feasibility study of oxaliplatin with oral S-1 or capecitabine as first-line therapy for patients with metastases from colorectal cancer. Anticancer Res 33: 4029-4032, 2013.

21. Jordà M and Peinado MA: Methods for DNA methylation analysis and applications in colon cancer. Mutat Res 693: 84-93, 2010.

22. Gyparaki MT, Basdra EK and Papavassiliou AG: DNA methylation biomarkers as diagnostic and prognostic tools in colorectal cancer. J Mol Med Berl 91: 1249-1256, 2013.

23. Motoyama K, Inoue H, Takatsuno Y, Tanaka F, Mimori K, Uetake H, Sugihara K and Mori M: Over- and under-expressed microRNAs in human colorectal cancer. Int J Oncol 34: 1069-1075, 2009.

24. Kaur S, Lotsari JE, Al-Sohaily S, Warusavitarne J, KohonenCorish MR and Peltomäki P: Identification of subgroup-specific miRNA patterns by epigenetic profiling of sporadic and Lynch syndrome-associated colorectal and endometrial carcinoma. Clin Epigenetics 7: 20, 2015.

25. Wang Y, Fu J, Jiang M, Zhang X, Cheng L, Xu X, Fan Z, Zhang J, Ye Q and Song H: MiR-410 is overexpressed in liver and colorectal tumors and enhances tumor cell growth by silencing FHL1 via a direct/indirect mechanism. PLoS One 9: e108708, 2014.

26. Slattery ML, Wolff E, Hoffman MD, Pellatt DF, Milash B and Wolff RK: MicroRNAs and colon and rectal cancer: Differential expression by tumor location and subtype. Genes Chromosomes Cancer 50: 196-206, 2011.

27. Peterson SM, Thompson JA, Ufkin ML, Sathyanarayana P, Liaw $L$ and Congdon CB: Common features of microRNA target prediction tools. Front Genet 5: 23, 2014.

28. Vlachos IS and Hatzigeorgiou AG: Online resources for miRNA analysis. Clin Biochem 46: 879-900, 2013.

29. Fernandes MS, Carneiro F, Oliveira $C$ and Seruca R: Colorectal cancer and RASSF family - a special emphasis on RASSF1A. Int J Cancer 132: 251-258, 2013.

30. Richter AM, Pfeifer GP and Dammann RH: The RASSF proteins in cancer; from epigenetic silencing to functional characterization. Biochim Biophys Acta 1796: 114-128, 2009.

31. Volodko N, Gordon M, Salla M, Ghazaleh HA and Baksh S: RASSF tumor suppressor gene family: Biological functions and regulation. FEBS Lett 588: 2671-2684, 2014. 